Article

\title{
Contingency Management and Supply Chain Performance in Korea: A COVID-19 Pandemic Approach
}

\author{
Segu Oh ${ }^{1}$, Hee Cheol Moon ${ }^{2}$ and Yongping Zhong ${ }^{2, *(1)}$ \\ 1 School of Business, Chungnam National University, 99 Daehak-ro, Yuseong-gu, Daejeon 34134, Korea; \\ nice69@cnu.ac.kr \\ 2 Department of International Trade, Chungnam National University, 99 Daehak-ro, Yuseong-gu, \\ Daejeon 34134, Korea; hcmoon@cnu.ac.kr \\ * Correspondence: yongping.zhong@hotmail.com
}

Received: 31 October 2020; Accepted: 23 November 2020; Published: 24 November 2020

\begin{abstract}
Unexpected incidents are driving global supply chains to the brink of collapse. To effectively manage contingency events like the COVID-19 pandemic and improve operational performance, factors such as information technology (IT), relational competencies, cooperation with supply chain partners and integration of supply chain systems that contribute to cooperation are essential. This study found that IT and relational competencies positively influence the integration of supply chain systems, and relational competencies have a stronger implication on supply chain integration and collaboration. In addition, supply chain collaboration, strengthened by supply chain integration, positively affects contingency management. Finally, contingency management positively influences operational performance. In this study, we adopted partial least squares structural equation modeling (PLS-SEM) method in the analysis with 102 surveys collected from business managers. Through the evaluation of determinants of contingency management and supply chain performance, this study widens the theoretical base of supply chain management and provides managers with optimal ways to build a more resilient supply chain system to cope with unexpected incidents. Consequently, with collaboration-based contingency management, companies can solve problems properly and reduce additional loss, which will enhance operational performance and enable sustainable business success.
\end{abstract}

Keywords: IT competency; relational competency; SC (supply chain) integration; SC (supply chain) collaboration; contingency management; operational performance; COVID-19

\section{Introduction}

Supply chain risk problems have become increasingly prominent in the academic discourse and practical field. Risk management of supply chains has attracted significant attention, because crises, disasters, globalization, and dynamic changes in the market have made the modern supply chain more vulnerable than ever [1]. According to Wieland and Wallenburg [2], supply chain risk management is the implementation of a strategy that aims to cope with daily and accidental risks within the supply chain. Complicated structures within the supply chain, caused by changes in the business environment inside and outside the supply chain, can lead to unpredictable business situations, such as inaccurate demand forecasts, product defects or damages, and delays in delivery, which can trigger accidental events and make the supply chain more vulnerable. As a part of supply chain risk management, the concept of contingency (accidental events) management was proposed in the early 2000s by Alvarenga and Schoenthaler [3] and Asgekar [4], and they also emphasized the importance of contingency. Contingencies including accidental events refer to incidents that are 
not premeditated or recognized in advance [5], as exemplified by the COVID-19 pandemic, the trade war between the United States and China, and other global events. If accidents in the supply chain cannot be properly controlled, they may pose a serious threat to the implementation of supply chain plans. The process cycle for managing these contingencies includes identifying and evaluating to controlling and monitoring the risks [6]. Additionally, managing supply chain risks positively impacts organization and supply chain management performance [7].

Due to the growth of globalization, businesses are more connected and more easily affected by rapid environmental changes. More resilient supply chains that can effectively cope with potential disruptions and unforeseeable accidental events are critical. Rapid globalization, market uncertainty and intensive competition force companies to seek new ways to improve responsiveness, efficiency, and quality of supply chain management. In the past, companies focused primarily on improvements within the organization, but recently, integration and collaboration are paramount to ensure supply chain management success, which requires companies to expand focus from organization to the entire supply chain. A supply chain includes all the organizations involved in the design, manufacturing, distribution, marketing, and retail process of a product or service [8]. It can be regarded as a meta-organization that is composed of independent organizations building inter-organizational relationships and integrating business systems together, which means that the management of a supply chain could be extremely complicated and requires a certain synchronization process [9]. For a company to gain strategic advantage, maximize profits, and increase market share, a collaborative strategy with partners has replaced previous stand-alone business strategies [10]. Additionally, to efficiently manage supply chain and accidental events, companies should establish a collaborative system. Furthermore, business globalization requires information integration inside and outside the organization within the supply chain because integration enhances forecasting and inventory replenishment of global production and marketing activities that enable an efficient response to rapidly changing requirements [11]. To better satisfy customer needs in such a dynamic environment, supply chain integration becomes more significant than ever in terms of creating opportunities for organizations to cooperate with supply chain partners. Supply chain risk also will diminish if supply chain integration is increased, and such integration is considered as an antecedent of customer satisfaction [12].

The key motivation of this study is to seek more efficient ways to improve contingency management capability of the supply chain to deal with accidental events such as the COVID-19 pandemic. Recently, a growing number of businesses worldwide have been affected by the COVID-19 pandemic due to national lockdowns and closed borders. It has brought huge shock to economies and caused problems in supply chains internationally, which has illustrated the fragility and vulnerability of the modern supply chain [13]. In the case of Korea, first infection cases of COVID-19 were reported on 20 January 2020 by the National IHR Focal Point (NFP) in the Republic of Korea [14]. Since then, new cases have been continuously reported within the country (see Figure 1), and the country has experienced many challenges. As the first and second waves of COVID-19 spread worldwide, companies must cope with accidental events more efficiently and minimize the disruptions of COVID-19 pandemic. Thus, it is important to identify decisive factors that positively drive contingency management and to investigate the relationship between contingency management and operational performance, through which we can unveil the managerial procedures to better handle such accidental events in the future.

In this study, IT competency and relationship competency are considered antecedents of supply chain integration and collaboration, which are indispensable foundations for companies to effectively manage supply chain risk. Supply chain integration requires the ability to invest in and use IT resources, meanwhile, if the relationships between companies are weak, collaboration and establishing an integrated supply chain management system may be impossible. If the supply chain management system can be strengthened by integration and collaboration with partners, it will positively influence operational performance through contingency management. Many previous studies have focused on supply chain networks that remain relatively stable, and most of them have mainly studied how integration/collaboration can be directly connected with firm performance [15-18], but none of them have 
investigated the antecedents such as IT competency and relational competency and linked them with integration and collaboration under the concept of contingency management. This study proposes a new and integrated model (Figure 2) that investigates the relationships among IT competency, relational competency, collaboration and integration of supply chain systems, and contingency management within the supply chain and, consequently, how contingency management can improve the firm performance. This study tries to solve the following research questions: (1) how can IT competency, relational competency, integration and collaboration of supply chain systems affect contingency management, and what are the correlations among these variables? (2) How can the efficient contingency management influence operational performance? (3) How can the key findings of this study be used to provide more insights to solve the problems caused by the pandemic? To answer these questions and test the model, basic statistical analysis and common method bias analysis were performed through SPSS; measurement model and structural model analysis were performed by using smartPLS.

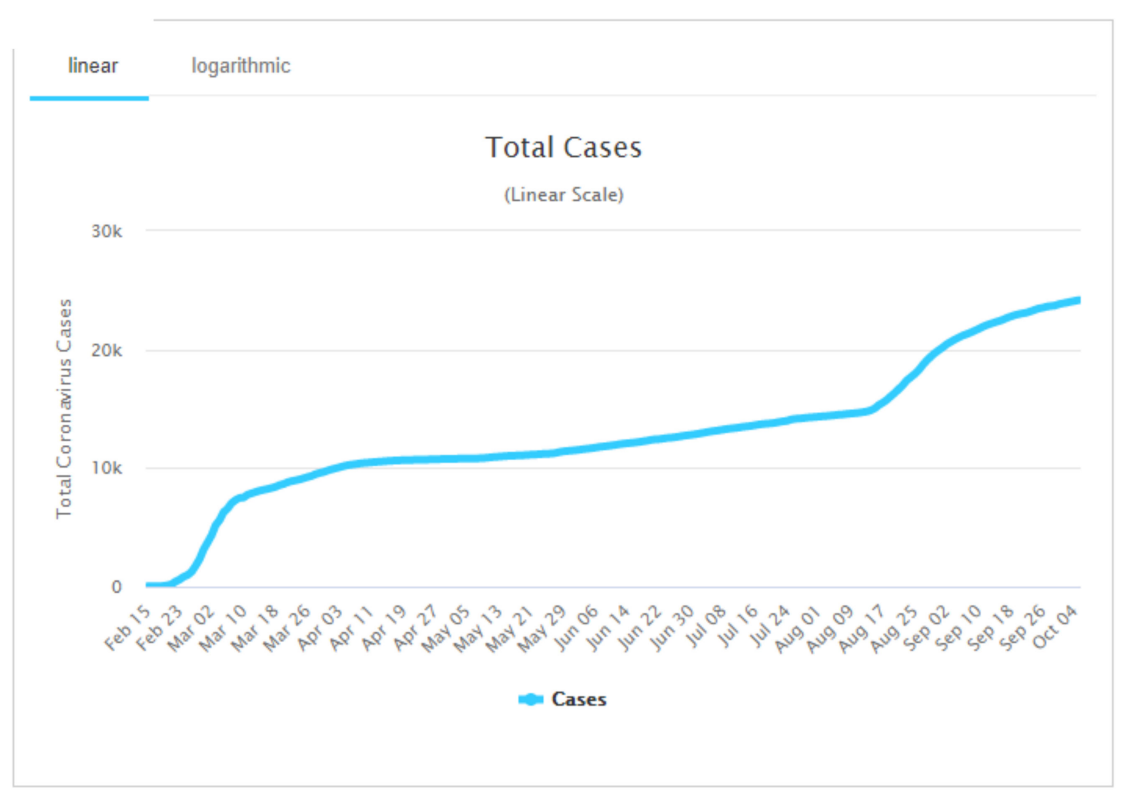

Figure 1. Total coronavirus cases in South Korea [19].

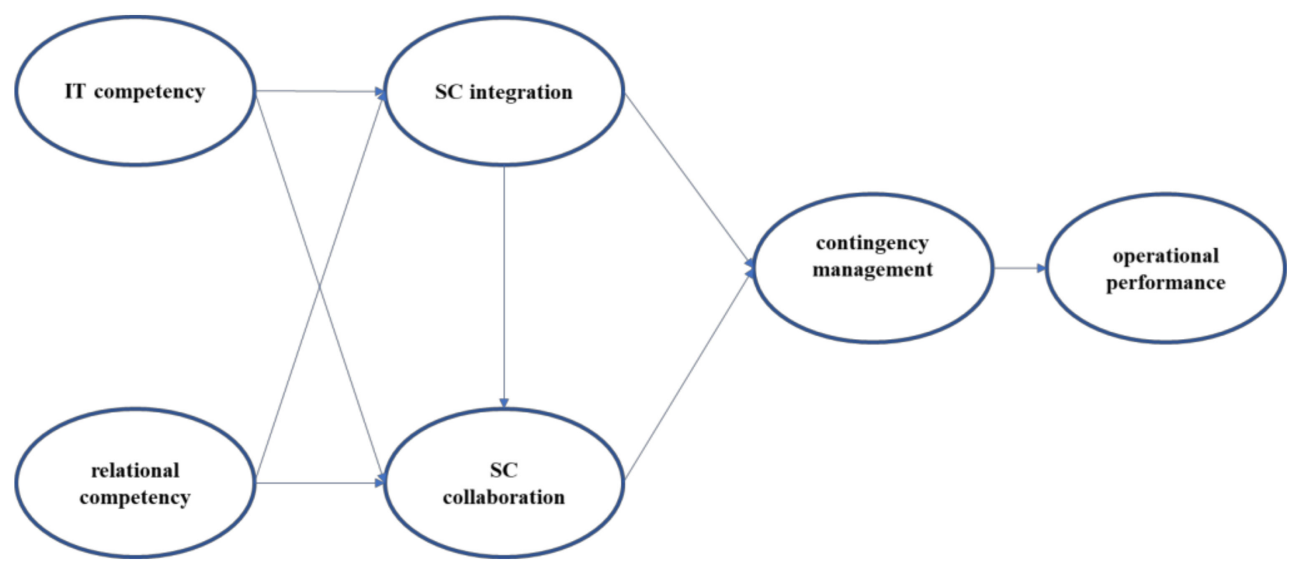

Figure 2. Proposed model.

This article is organized as follows: Following this introduction and background section, we introduce the background of this research; Section 2 presents the literature review and hypotheses development. Section 3 outlines the research methodology, and Section 4 reveals the analysis results. Section 5 discusses accidental events such as the COVID-19 pandemic and concludes. 


\section{Literature Review and Hypotheses Development}

\subsection{IT Competency, SC (Supply Chain) Integration, and SC Collaboration}

Based on Porter's value chain theory [20], a company's supply chain can be divided into a series of major activities, including inbound logistics, outbound logistics, operations, marketing and sales, service, and support services. These activities are either proceeding inside or outside the organization, and they share a common goal of creating value for the end customer [21]. To achieve this goal, collaboration and integration inside and outside the organization are critical, and when achieved successfully, they may lead to cost savings by eliminating redundant operations and waste of resources.

Many scholars argued that external suppliers, transportation partners, and customers should be connected to achieve collaboration and integration within the supply chain [22-25], which requires accurate and timely information between supply chain partners. With information technology and reliable relationships that companies build together, this will enhance the information sharing within the supply chain, reduce the uncertainty, and enable companies to response to customer demands more properly; advanced information technologies of software or hardware can facilitate firms to organize and operate efficiently [26]. Therefore, the capability to manage information flow through IT infrastructures directly affects the survival of companies. The IT competency of enterprises is a crucial driver of supply chain integration and collaboration that enables the capturing, organizing, and sharing of important information related to key business processes inside and outside the organization [27].

Thus, the following hypotheses are proposed:

Hypothesis 1 (H1). A company's IT competency have a positive effect on the integration within the supply chain.

Hypothesis 2 (H2). A company's IT competency have a positive effect on company collaboration within the supply chain.

\subsection{Relational Competency, SC Integration, and SC Collaboration}

In the past, companies competed independently; however, today companies must collaborate to gain synergy. It is rare that a product is produced by a single company from start to finish. Collaboration between different companies is routine for a company, which relies on relationship capacity. Relational competency definitions might vary, but the key content remains the same. Paulraj et al. (2008) defined relational competency as communication between companies based on a relational view that could continuously increase its competitive advantage [28]. Kale et al. (2000) argued that relational competency can significantly drive the acquisition of new skills and strengthen one's capabilities during the collaboration between companies [29]. Similarly, Park (2015) defined it as the capability to manage relationships by accumulated knowledge, unique ability, and trust within the companies [30].

Relational competency is a crucial factor within the supply chain that both determines and strengthens the partnership. Relational competency can improve supply chain performance by influencing the patterns of supply chain activities. According to Wu et al. (2014), relational competency (mutual trust, dedication, and benefits) within the supply chain enables information sharing and enhances cooperation among trading partners [15]. Relational competency allows supply chain partners to focus on common goals, decision-making, and establishing partnerships [31]. Wittman et al. (2009) emphasized the importance of relationship immersion, trust, and communication, which are fundamental elements of relational competency and significantly impact business cooperation [32]. Through relational competency, companies enhance activities throughout the entire supply chain and facilitate an integration of the system and internal/external resources.

Thus, the following hypotheses can be proposed:

Hypothesis 3 (H3). A company's relational competency has a positive effect on the integration within the supply chains. 
Hypothesis 4 (H4). A company's relational competency has a positive effect on collaboration within the supply chain.

\subsection{SC Integration, SC Collaboration and Contingency Management}

Kim and Park (2016) stated that information technology could improve business performance and competitiveness of the supply chain by integrating various functional areas within the company and effectively linking them to the activities of suppliers, distributors, and customers [27]. Many studies indicated that the integration of a supply chain is conducted from two aspects: internal integration and external integration [27,33]. Internal integration means utilizing information technology to synchronize all internal functions from the management of raw materials to production, transportation, and sales. Many departments within the supply chain have different responsibilities and authorities, making integrated management difficult. A key goal for integrated logistics is to operate properly, and to achieve this goal, an integrated information system is critical. The integrated information system allows the relevant departments to share information and make work more transparent, which contributes to information flow of operational processes and products. System integration of the supply chain is necessary to manage and control the flow of the operating system. Controlling this flow impacts inventory management and activity planning. By controlling the flow, firms have competitive advantages in terms of quality, speed, reliability, flexibility, and cost of the operating systems [34-36].

Regarding external integration, the scope of organizational integration is extended from internal to external, meaning connection with customers, suppliers, supplier affiliates, and producers. Market, production, and delivery information shared between partners can improve decisions on cooperative plans, forecasting, replenishment, as well as allocating resources, activities, and roles within the supply chain [15]. Thus, such supply chain integration based on information sharing is realized by mutual communication between trading partners, which is a type of collaboration among supply chain members.

To increase the competitiveness within the supply chain, it requires extensive integration and collaboration [37]. More significantly, supply chain risk management largely relies on the coordination or collaboration among partners or members of supply chain [38], and it is also closely associated with risk information sharing that enable companies to check the safety of the whole supply chain and to prepare for certain threats [39]. If the supply chain has effectively achieved internal integration on information sharing and collaboration between external partners (external integration), the company can access real-time information about activities upstream and downstream in the supply chain. Without supply chain information sharing, participants cannot recognize demand changes caused by contingencies downstream, which may lead to a whip effect causing redundant inventory and extra costs. Therefore, to avoid such problems caused by accidental events, companies should strengthen internal and external integration of supply chains to facilitate contingency management.

Thus, the following hypotheses can be proposed:

Hypothesis 5 (H5). Integration within supply chain has a positive effect on collaboration.

Hypothesis 6 (H6). Integration within supply chain has a positive effect on contingency management.

Hypothesis 7 (H7). Collaboration within the supply chain has a positive effect on contingency management.

\subsection{Contingency Management and Operational Performance}

In decision making, lack of accurate information may cause uncertainty. To provide good information and reduce uncertainty, companies should share information throughout the supply chain [40]. For an organization to effectively manage contingencies in the supply chain, supply chain visibility must be ensured, so that information regarding all activities upstream and downstream can be checked in real 
time. Companies, including suppliers, should be aware of customer-related contingencies downstream. When real-time information is available, companies can improve performance by identifying accidental events more easily. Managers can use flows of online information to keep updated with suppliers and customers and gain competitive advantages. Risk management of supply chain activities positively influences operational and supply chain management performance [1]. If companies can effectively manage contingencies within the supply chain, they might experience strong competitive advantages [5]. Hence, supply chain productivity can improve if a company can respond immediately to accidental events.

Thus, the following hypotheses can be proposed:

Hypothesis 8 (H8). Contingency management has a positive effect on operational performance.

\section{Methodology}

\subsection{Sample and Data Collection}

Table 1 presents the demographic information of the sample used in this study. The data were gathered during January and February 2020 from the Small and Medium Enterprises information websites (http://www.sminfo.mss.go.kr) organized by the Ministry of SMEs and Startups in Korea. After making phone calls to the related companies, a questionnaire was sent via email to companies that agreed to participate in the research. The targeted respondents were managers of SMEs located in cities, including Seoul, Gyeonggi, Changwon, Busan, and Ulsan. A total of 124 questionnaires were collected, of which 102 questionnaires were used in the analysis, as questionnaires with incomplete answers were excluded. The 102 companies represented various industries and have maintained transactions with major trading companies, on average for 9.66 years. More than half of the companies have USD 4,200,000 annual sales, and only $2.9 \%$ of companies have less than USD 250,000 annual sales.

Table 1. Sample profile.

\begin{tabular}{|c|c|c|c|c|}
\hline & Characteristics & Frequency & Percentage & $\begin{array}{c}\text { Cumulative } \\
\text { Percentage (\%) }\end{array}$ \\
\hline \multirow{7}{*}{ Product type } & Consumption products & 12 & 11.8 & 11.8 \\
\hline & Production products & 12 & 11.8 & 23.5 \\
\hline & Intermediate products & 14 & 13.7 & 37.3 \\
\hline & Service products & 22 & 21.6 & 58.8 \\
\hline & General products and Services products & 30 & 29.3 & 88.2 \\
\hline & others & 12 & 11.8 & 100 \\
\hline & total & 102 & 100 & - \\
\hline \multirow{5}{*}{$\begin{array}{l}\text { Annual sales } \\
\text { (originally } \\
\text { calculated in KRW) }\end{array}$} & less than USD 250,000 & 3 & 2.9 & 2.9 \\
\hline & USD 250,001 420,000. & 14 & 13.7 & 16.7 \\
\hline & USD 420,001 840,000 & 6 & 5.9 & 22.5 \\
\hline & USD $840,001 \sim 4,200,000$ & 12 & 11.8 & 34.3 \\
\hline & over USD 4,200,000 & 67 & 65.7 & 100.0 \\
\hline
\end{tabular}

\subsection{Measurement of Constructs}

In this study, we adopted a 7-point Likert scale ( 1 = strongly disagree; $7=$ strongly agree). SPSS 26 was utilized for the descriptive analysis. Moreover, the partial least squares structural equation modeling (PLS-SEM) method was applied using SmartPLS 2.0 software to conduct reliability analysis, confirmatory factor analysis, and path analysis. In this study, we tried to solve common method bias in both the questionnaire design and data analysis stage. When we designed the questionnaire, concise and clear items were developed based on related studies. In addition, these items were modified after pilot interviews with company managers. In the data analysis stage, a single factor test of Harman was performed [41]. As a result of performing a single factor analysis with all measurement items, the results showed that the maximum percentage of variance was 0.384 , which indicates that common method bias was not an issue as it was less than the standard value of 0.5 . 
Items of IT competency, relational competency, supplier chain system integration, supply chain collaboration, contingency management, and operational performance were mainly adopted from previous studies (see Appendix A), and each of the construct includes 3-5 items.

\section{Analysis and Results}

In this study, SmartPLS was used to test the proposed hypotheses. Partial least squares (PLS) is a statistical technique that enables optimal empirical evaluation of the theoretical measurement model and structural model and is comparatively less limited by sample size than the general structural equation program. In PLS, the loading value of each construct is estimated; then, the mutual relationship between constructs is evaluated [36]. We adopted the PLS method for the following reasons: PLS is more suitable for small sample sizes compared to general structural equation programs; it is suitable for analyzing correlations of constructs with less focus on the fitness of the entire model.

\subsection{Measurement Model Result}

Measurement models are generally evaluated using convergent validity and discriminant validity. Convergent validity is evaluated by composite reliability (CR) and average variance extracted (AVE) of each factor. Discriminant validity is tested by the loading value of each factor; if the square root of AVE of each factor is higher than the inter-construct correlation, this indicates a good level of discriminant validity [42-44]. As a result of the measurement model, the loading value of each item was above 0.5 , with a significant $t$-value (Table 2). In addition, the CR was all above 0.7 , and the AVE value was also above the recommended value of 0.5 [43]. Thus, the convergent validity between the concepts in the measurement model was appropriate. Discriminant validity was also found to be consistent with the requirements, indicating a satisfactory level of discriminant validity (Table 3).

Table 2. Descriptive statistics and factor loading results.

\begin{tabular}{|c|c|c|c|c|c|c|}
\hline \multirow{2}{*}{ Construct } & \multicolumn{6}{|c|}{ Results } \\
\hline & Item & Mean & S.D & Factor Loading & S.E & t-Value \\
\hline \multirow{4}{*}{ IT competency } & IT1 & 4.37 & 2.000 & 0.898 & 0.034 & 26.507 \\
\hline & IT2 & 4.14 & 1.835 & 0.939 & 0.015 & 61.484 \\
\hline & IT3 & 4.29 & 1.973 & 0.959 & 0.013 & 71.157 \\
\hline & IT4 & 3.87 & 1.811 & 0.509 & 0.133 & 3.819 \\
\hline \multirow{5}{*}{ Relational competency } & $\mathrm{RC} 1$ & 5.17 & 1.328 & 0.784 & 0.052 & 15.149 \\
\hline & $\mathrm{RC} 2$ & 5.12 & 1.084 & 0.869 & 0.038 & 23.123 \\
\hline & $\mathrm{RC} 3$ & 4.66 & 1.010 & 0.788 & 0.056 & 14.193 \\
\hline & $\mathrm{RC} 4$ & 5.12 & 0.968 & 0.876 & 0.025 & 34.764 \\
\hline & RC5 & 5.14 & 0.985 & 0.862 & 0.023 & 37.402 \\
\hline \multirow{3}{*}{ Supply chain integration } & SCI1 & 5.24 & 1.574 & 0.936 & 0.016 & 60.163 \\
\hline & SCI2 & 5.27 & 1.394 & 0.935 & 0.014 & 65.795 \\
\hline & SCI3 & 4.81 & 1.767 & 0.832 & 0.033 & 25.087 \\
\hline \multirow{5}{*}{ Supply chain collaboration } & SCC1 & 4.75 & 1.433 & 0.835 & 0.030 & 27.712 \\
\hline & SCC2 & 4.75 & 1.295 & 0.840 & 0.036 & 23.073 \\
\hline & SCC3 & 4.50 & 1.272 & 0.792 & 0.049 & 16.334 \\
\hline & SCC4 & 4.83 & 1.394 & 0.870 & 0.028 & 31.494 \\
\hline & SCC5 & 5.30 & 1.356 & 0.819 & 0.041 & 19.966 \\
\hline \multirow{5}{*}{ Contingency management } & CM1 & 4.55 & 1.621 & 0.790 & 0.064 & 12.346 \\
\hline & CM2 & 4.25 & 1.760 & 0.841 & 0.049 & 17.265 \\
\hline & $\mathrm{CM} 3$ & 5.14 & 1.712 & 0.738 & 0.053 & 13.957 \\
\hline & CM4 & 4.44 & 1.657 & 0.854 & 0.034 & 25.000 \\
\hline & CM5 & 4.23 & 1.908 & 0.835 & 0.054 & 15.614 \\
\hline
\end{tabular}


Table 2. Cont.

\begin{tabular}{ccccccc}
\hline \multirow{2}{*}{ Construct } & \multicolumn{7}{c}{ Results } \\
\cline { 2 - 7 } & Item & Mean & S.D & Factor Loading & S.E & t-Value \\
\hline \multirow{3}{*}{ Operational performance } & OP1 & 5.23 & 1.258 & 0.688 & 0.074 & 9.249 \\
& OP2 & 4.66 & 1.020 & 0.647 & 0.087 & 7.414 \\
& OP3 & 4.11 & 1.455 & 0.666 & 0.101 & 6.593 \\
& OP4 & 5.04 & 1.435 & 0.880 & 0.027 & 32.728 \\
& OP5 & 4.83 & 1.343 & 0.812 & 0.044 & 18.352 \\
\hline
\end{tabular}

Note: S.D. = standard deviation; S.E. = standard error; IT = IT competency; RC = relational competency; SCI = supply chain integration; $\mathrm{SCC}=$ supply chain collaboration; $\mathrm{CM}=$ contingency management; $\mathrm{OP}=$ operational performance.

Table 3. Construct reliability, convergent validity and Fornell-Larcker criterion.

\begin{tabular}{ccccccc}
\hline & $\mathbf{1}$ & $\mathbf{2}$ & $\mathbf{3}$ & $\mathbf{4}$ & $\mathbf{5}$ & $\mathbf{6}$ \\
\hline IT competency (1) & $(0.847)$ & & & & & \\
Relational competency (2) & 0.207 & $(0.837)$ & & & & \\
Supply chain integration (3) & 0.399 & 0.641 & $(0.902)$ & & & \\
Supply chain collaboration (4) & 0.410 & 0.598 & 0.628 & $(0.832)$ & & \\
Contingency management (5) & 0.596 & 0.431 & 0.495 & 0.559 & $(0.811)$ & \\
Operational performance (6) & 0.479 & 0.541 & 0.670 & 0.682 & 0.569 & $(0.742)$ \\
AVE & 0.717 & 0.700 & 0.814 & 0.692 & 0.658 & 0.550 \\
Compositive reliability & 0.906 & 0.921 & 0.929 & 0.918 & 0.906 & 0.856 \\
Cronbach's alpha & 0.863 & 0.893 & 0.884 & 0.889 & 0.875 & 0.798 \\
\hline
\end{tabular}

Note: All correlation coefficients are significant at $\alpha=0.05$ level. Diagonal values in Table 3 are the square root of AVE (average variance extracted). For adequate discriminant validity, diagonal values should be greater than corresponding off-diagonal elements.

\subsection{Structural Model Result}

In Section 4.1, the reliability and validity of the measurement model were confirmed. In this section, we examine the results of the structural model, which checks the relationships between constructs. To evaluate the structural model in the PLS structural equation, the following three aspects are extremely important: the value of $R^{2}$, the significance of the path coefficient and diagnosis of multicollinearity.

As shown in Figure 3, $\mathrm{R}^{2}$ in the research model ranges from 0.347 to 0.588. In PLS, the higher the $\mathrm{R}^{2}$ of the model, the better the fit. Therefore, considering the $\mathrm{R}^{2}$ of this study, the model fitness is suitable. The significance of internal causations among constructs was confirmed. As a result of the research model, the path coefficient was 0.21-0.591, indicating no problem in interpreting the relationship between the concepts. Finally, the criterion for testing multicollinearity is less than 5; in this study all the VIF (Variance inflation factor) values were less than 3, which indicates that there was no multicollinearity problem. 


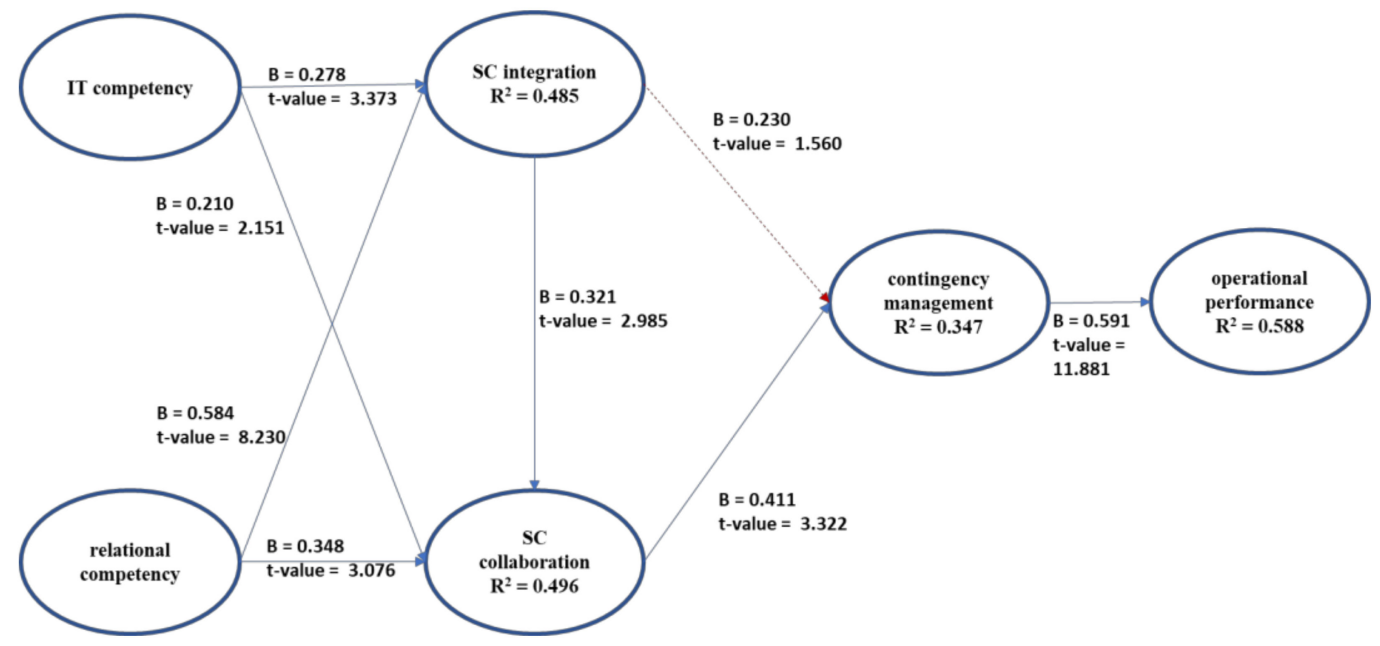

Figure 3. Structural model result.

\subsection{Hypotheses Testing Result}

Based on the research model, the relationships among the capabilities of companies, supply chain integration and cooperation, and operational performance are confirmed (Figure 3 and Table 4). We found that the IT competency of a company had a significant effect on both supply chain integration $(\beta=0.278$, $t$-value $=3.373)$ and supply chain collaboration $(0.210, t$-value $=2.151)$, which supports $\mathrm{H} 1$ and $\mathrm{H} 2$. Relational competency was found to have a strong influence on supply chain integration $(\beta=0.584$, $t$-value $=8.230)$ and supply chain collaboration $(\beta=0.348, t$-value $=3.076)$, which supports $\mathrm{H} 3$ and H4. Hence, if a company has a positive relationship with its current trading partners, this enhances the integration of information systems and collaboration between companies. In addition, we found that supply chain integration positively impacts collaboration $(\beta=0.321, t$-value $=2.985$, confirming H5), indicating that when the information system is integrated with the trading partner, collaboration with the partners in the supply chain is also strengthened. However, the results showed that supply chain integration did not have a significant effect on contingency management $(\beta=0.230$, $\mathrm{t}$-value $=1.560$, rejecting $\mathrm{H6}$ ), while supply chain collaboration did have a relatively strong effect on contingency management ( $\beta=0.411$, $t$-value $=3.322$, supporting H7). Both supply chain integration and supply chain cooperation are critical for contingency management. However, even if real-time information sharing is in place, effectively managing accidental events requires cooperating with partners. The integration of information systems enables real-time information sharing and transaction processing with trading partners, and, as a result, it contributes to collaboration within the supply chain and improves contingency management. Finally, the results revealed that contingency management could statistically affect operational performance $(\beta=0.591$, t-value $=11.881$, supporting $\mathrm{H} 8)$, which means an efficient contingency management system can improve company performance.

Table 4. Testing results of hypotheses.

\begin{tabular}{cccc}
\hline Path & Estimate & S.E & t-Value \\
\hline H1: IT competency -> SC integration & 0.278 & 0.083 & 3.373 \\
H2: IT competency -> SC collaboration & 0.210 & 0.098 & 2.151 \\
H3: Relational competency-> SC integration & 0.584 & 0.071 & 8.230 \\
H4: Relational competency -> SC collaboration & 0.348 & 0.113 & 3.076 \\
H5: SC integration -> SC collaboration & 0.321 & 0.107 & 2.985 \\
H6: SC integration-> Contingency management & 0.230 & 0.147 & 1.560 \\
H7: SC collaboration -> Contingency management & 0.411 & 0.124 & 3.322 \\
H8: Contingency management -> Operational performance & 0.591 & 0.050 & 11.881 \\
\hline
\end{tabular}




\section{Discussion and Conclusions}

\subsection{Implications}

In recent years, the biggest challenge for supply chain management is coping with accidental events. The occurrence of unexpected events, such as the COVID-19 outbreak, has disrupted global supply chains. Therefore, contingency management is increasingly important to effectively manage accidental events inside the supply chain. To effectively manage contingency events, companies must actively cooperate with supply chain partners and integrate supply chain systems that support cooperation.

Based on the findings, it was observed that IT and relational competencies have a positive effect on the integration of supply chain systems, and relational competencies have a stronger impact on supply chain integration and collaboration. Therefore, companies should invest in IT infrastructure to facilitate communication, transactions, and cooperation among suppliers, manufacturers, distributors, and customers. It is extremely critical for companies to build a digital supply chain through IT facilities, which enables smarter transactions. Currently, information free flow is vital, and companies should also endeavor to build integrated systems to ensure information sharing through advanced IT resources, leading to digitalization of supply chains. Companies should be aware that a digital supply chain is key to resilience as it increases the visibility and flow of information. A digitalized supply chain is a long-term solution that can build a resilient supply chain to handle accidental events, like COVID-19 [13]. For managers, a resilient supply chain should be built through advanced technologies such as the Internet of Things, artificial intelligence, robotics, and 5G [45]. More importantly, in a network system such as a supply chain, operational performance relies more on cooperative relationships between companies than on company capabilities. Establishing relationship capabilities enables information sharing and collaboration between organizations, which should not be neglected by businesses. Companies should be aware that it is beneficial to maintain a long-term trustworthy relationships and make adjustment accordingly to build collaboration partnership. This is because when the relationship between companies strengthens, the level of cooperation between companies deepens.

We also found that supply chain system integration that enhances information flow strengthens supply chain collaboration. Companies should strengthen relationships with partners through information and knowledge sharing as well as through a willingness to adapt strategies accordingly whenever conflicts or problems arise. Specifically considering accidental events like the COVID-19 pandemic, it increases uncertainty in the global environment and requires companies to consider additional risk factors before making decisions. However, it is important for mangers to know that reducing risks requires building an integrated database to exchange information online with partners. Even if such unpredictable accidental events occur, close cooperation enhanced by effective information sharing between partners can decrease the uncertainty of environmental change. It is crucial that companies should build an integrated online database/system that supports information or knowledge sharing to facilitate collaborations between partners.

Finally, the results revealed that supply chain collaboration can directly impact on contingency management and, consequently, increase companies' performance. Businesses should work on collaborations to build efficient channels for mutual communication and enhance information/knowledge exchange. They should cooperate to establish a connected online transaction platform or database, which may reduce transaction costs and time and enhance information sharing for real-time inventory, customer demands, accidental events, and transaction processes. All of these may improve accidental event management and business performance in the long term.

\subsection{Contingency Management during the COVID-19 Pandemic: A Case Discussion Focusing on Korea}

Recently, during the COVID-19 pandemic, managers that clearly understand their vulnerabilities and partners could take advantage of the pandemic situation. To build a more resilient supply chain in such accidental events, an integrated information sharing system and close cooperation are essential. 
Meanwhile, relational and IT competency can also help firms to gain more competitive advantages in dealing with contingencies. All of these can be supported by the following case discussions in Korea:

Due to customer panic buying and national lockdowns, there were rapid changes in demand for certain products, including food, beverages, and cleaning products, but real-time information exchange through an integrated online database/system for products, inventory, and customer needs could have helped companies prepare. In Korea, as the number of cases surged in February in the worst-hit city of Daegu, citizens flocked to groceries and left behind barren shelves. Essential foods, including eggs, fresh meat, and milk, sold out rapidly at local supermarkets [46]. However, unlike in the US or Europe, there was little panic buying reported throughout Korea. Many experts said that information-technology-based delivery systems in Korea prevented panic buying. The well-designed and easy-to-use delivery system reduced pressure of panic buying. Such delivery services largely depend on IT infrastructures, online transaction platforms, and the use of smart phones [47], which offered channels to exchange information and products among suppliers, distributors, and customers. Similar delivery service can be built by companies in other countries with advanced IT infrastructures, online transaction platforms, and the use of smart phones.

Additionally, the pandemic initially caused disruptions on the protective mask supply chain, but suppliers worked with local governments to establish a more transparent and integrated information-sharing system for mask inventory management. To manage the inventory efficiently and allow people access to masks, the government created a streamlined system through an app and website for people to have real-time information on mask availability at stores or pharmacies [48]. This integrated information-sharing system built with IT is useful on mask inventory management, which allowed distributors to transfer inventory information more promptly to the National Information Society Agency and to suppliers, which strengthened the effective cooperation. The system enabled immediate information-sharing on mask inventory for customers, distributors, and suppliers, which also strengthened cooperation within the supply chain. Additionally, the system helped consumers remain calm, as they had access to inventory data showing that many stores remained well stocked. Real-time online information exchange and efficient collaboration between distributors and suppliers through this system kept the mask supply chain visible and reliable. Thus, managers should realize that building such a transparent supply chain system with inventory information can reduce panic buying of certain goods, balance the overstock or shortage problem across different areas, and allow consumers to find alternatives. Consequently, it can reduce inventory management costs and relieve contingency management stress. If real-time information exchange on inventory is organized for customers, suppliers, and distributors across different stores and areas, companies can manage inventory more effectively through supply chain integration and cooperation. Hence, such a system can aid in handling accidental events.

Companies who maintain long-term relationships with strong relational competency and cooperated closely with diverse partners could have advantages in dealing with accidental events. Based on manufacturing capacity and inventory information shared between close partners from different sources, if accidental events cause huge demands on certain goods, companies could act promptly and find alternative sources more quickly. Lessons can be learned from the COVID-19 pandemic. For example, according to the Peterson Institute for International Economics [49], China is the major global supplier to many countries (including Korea) in terms of personal protective equipment (PPE). However, after COVID-19 cases surged during the spring of 2020, the increased demand for PPE inside China reduced availability of Chinese exports to other countries. Heavily relying on PPE exports from China caused Korea to suffer, as buyer companies did not expect the outbreak and most overwhelmingly depended on a single supplier. However, if buyer companies can build good relationships and cooperate closely with several suppliers and build a shared inventory information system, in this case, they could obtain real-time inventory information from different partners simultaneously and find alternatives more promptly, including those outside of China. While purchasing PPE from suppliers worldwide may be difficult currently, buyer companies can purchase 
small amounts from several suppliers if shared inventory information indicates availability of extra inventory. Thus, collaborating with diverse suppliers is highly recommended to cope with accidental events or disruptions [13,50], and real-time inventory information should be shared between partners to help companies handle accidental events efficiently. Similarly, suppliers should maintain close relationships and collaborate with several distributors or diverse buyers in different markets through a shared information system. When order information is delivered timely from buyers in each market, suppliers can be prepared for sudden reduced demands from one buyer or market by delivering products to alternative markets or buyers. Hence, the risk of overstock is significantly decreased, which can help businesses survive in the midst of accidental events.

Thus, managers should realize that companies should form close collaboration in regard to information/knowledge exchange of real-time inventory, customer information, accidental events, and transaction processes with partners, which enhances effective communication and fosters mutual understanding. As a result, this can help to handle delivery problems, overstocks, and shortages of raw material/products within the supply chain caused by a pandemic.

\subsection{Conclusions and Limitations}

Overall, a more efficient and rapid way to deal with contingent incidents requires companies to cooperate closely with partners and offer timely information sharing through an integrated information system that enhances supply chain collaboration. In this study, we found that supply chain integration and collaboration are built on certain relational and IT competency; contingency management relies on a close collaboration among partners that can be enhanced through real-time information sharing on products, customers, and suppliers' inventory; an efficient contingency management may help companies respond to problems more promptly and reduce further losses.

This study, under the background of COVID-19 pandemic, provides a comprehensive and better understanding on contingency management, but it also has certain limitations. First, the sample size is small. Because the participants were from management team, it could be difficult to obtain a significant amount of feedback. However, the conceptual model could be better tested for refinement and validity with more participants. Therefore, it may be difficult to generalize the results of this study to all industries. Researchers could extend our findings by including more participants in future studies. Second, the measurement of operational performance might be subjective depending on survey feedback. Hence, different contexts might elicit different results. Future research should measure operational performance using various sources with objective data. Third, other factors, such as top management support and firm size, can influence contingency management, which would impact operational performance. New variables may be included in future research to further examine the influence of contingency management on firm performance.

Author Contributions: Conceptualization, S.O. and Y.Z.; methodology, S.O.; formal analysis, S.O.; investigation, S.O.; writing — original draft preparation, S.O. and Y.Z.; writing—review and editing, S.O., H.C.M. and Y.Z.; supervision, Y.Z.; project administration, H.C.M.; funding acquisition, H.C.M. All authors have read and agreed to the published version of the manuscript.

Funding: This research was funded by the Ministry of Education of the Republic of Korea and the National Research Foundation of Korea, grant number NRF-2018S1A5B8070344.

Conflicts of Interest: The authors declare no conflict of interest. 


\section{Appendix A}

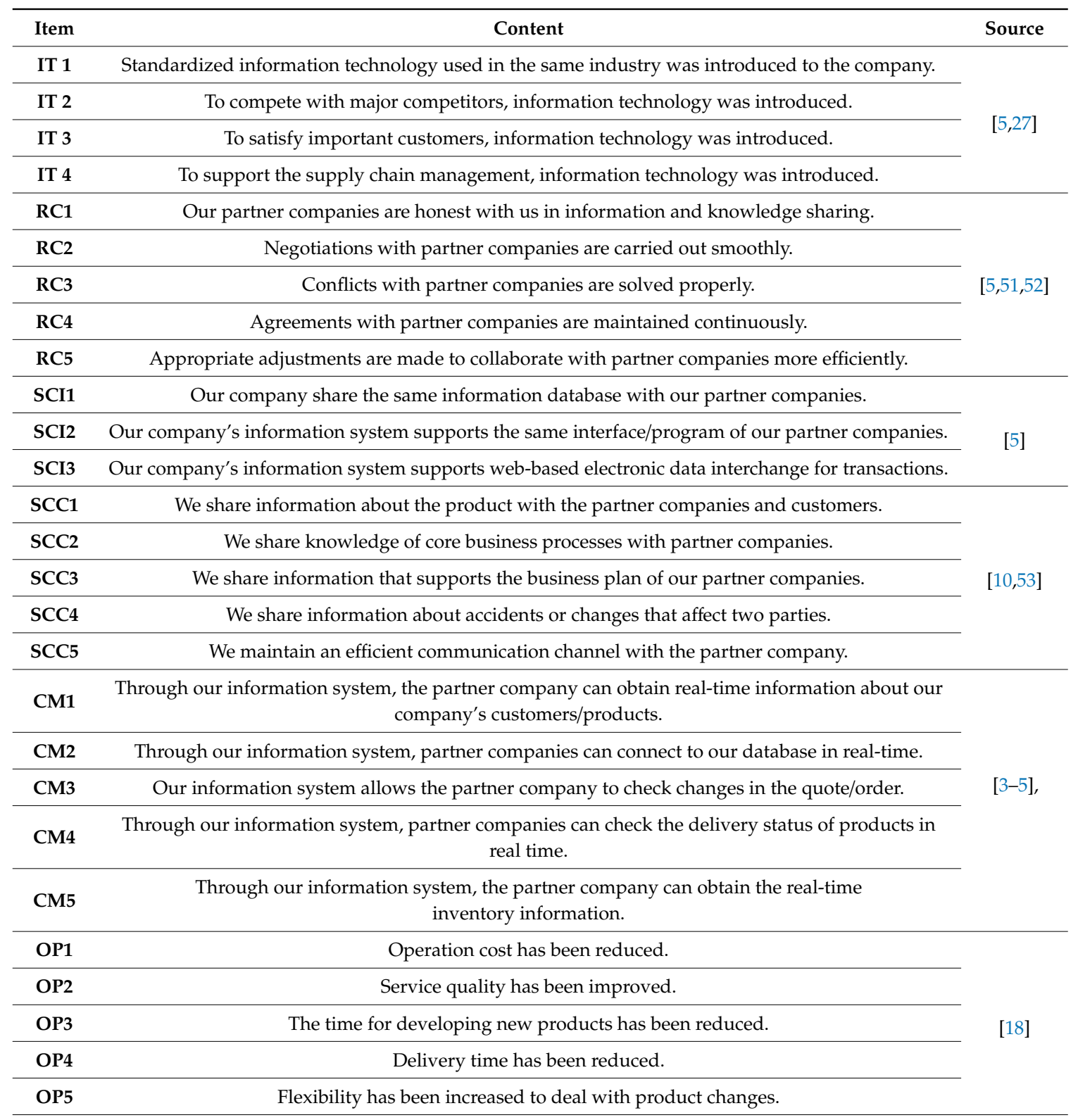

IT = IT competency; RC = relational competency; SCI = supply chain integration; SCC = supply chain collaboration;

$\mathrm{CM}=$ contingency management; $\mathrm{OP}=$ operational performance.

\section{References}

1. Hoffmann, P.; Schiele, H.; Krabbendam, K. Uncertainty, supply risk management and their impact on performance. J. Supply Manag. 2013, 19, 199-211. [CrossRef]

2. Wieland, A.; Wallenburg, C.M. Dealing with supply chain risks. Int. J. Phys. Distrib. Logist. Manag. 2012, 42, 887-905. [CrossRef]

3. Alvarenga, C.A.; Schoenthaler, R.C. A new take on supply chain event management. Supply chain management review. Supply Chain Manag. Rev. 2003, 7, 28-35.

4. Asgekar, V. Technology: Event Management Graduates with Distinction. Supply Chain Manag. Rev. 2003, 7, 15-18.

5. Kim, H.; Oh, S. Impact of trust and system integration on supply chain event management and information sharing. Prod. Rev. 2013, 27, 285-306.

6. Tummala, V.R.; Schoenherr, T. An implementation decision framework for supply chain management: A case study. Int. J. Logist. Syst. Manag. 2011, 8, 198-213. [CrossRef] 
7. Wagner, S.M.; Bode, C. An empirical examination of supply chain performance along several dimensions of risk. J. Bus. Logist. 2008, 29, 307-325. [CrossRef]

8. Holland, C.P.; Lockett, G.; Richard, J.M.; Blackman, I. The evolution of a global cash management system. Sloan Manag. Rev. 1994, 36, 37.

9. Zimon, D.; Madzík, P. Standardized management systems and risk management in the supply chain. Int. J. Qual. Reliab. Manag. 2019, 37, 305-327. [CrossRef]

10. Oh, S. The Affect of Building Cross-Enterprise Collaborative Environment and Trust on Operational Performance-From the Perspective of an Integrated Supply Chain. J. Korean Prod. Oper. Manag. Soc. 2010, 21, 71-81.

11. Wong, C.W.; Lai, K.H.; Bernroider, E.W. The performance of contingencies of supply chain information integration: The roles of product and market complexity. Int. J. Prod. Econ. 2015, 165, 1-11. [CrossRef]

12. Kros, J.F.; Falasca, M.; Dellana, S.; Rowe, W.J. Mitigating counterfeit risk in the supply chain: An empirical study. TQM J. 2019, 32, 983-1002. [CrossRef]

13. Zhu, G.; Chou, M.C.; Tsai, C.W. Lessons Learned from the COVID-19 pandemic exposing the shortcomings of current supply chain operations: A long-term prescriptive offering. Sustainability 2020, 12, 5858. [CrossRef]

14. World Health Organization. Novel Coronavirus-Republic of Korea (ex-China). Available online: https: //www.who.int/csr/don/21-january-2020-novel-coronavirus-republic-of-korea-ex-china/en/ (accessed on 5 October 2020).

15. Wu, L.; Chuang, C.H.; Hsu, C.H. Information sharing and collaborative behaviors in enabling supply chain performance: A social exchange perspective. Int. J. Prod. Econ. 2014, 148, 122-132. [CrossRef]

16. Yuen, K.F.; Van Thai, V. The influence of supply chain integration on operational performance. Int. J. Logist. Manag. 2017, 28, 444-463. [CrossRef]

17. Cao, M.; Zhang, Q. Supply chain collaboration: Impact on collaborative advantage and firm performance. J. Oper. Manag. 2011, 29, 163-180. [CrossRef]

18. Koçoğlu, İ.; İmamoğlu, S.Z.; İnce, H.; Keskin, H. The effect of supply chain integration on information sharing: Enhancing the supply chain performance. Proc. Soc. Behav. Sci. 2011, 24, 1630-1649. [CrossRef]

19. Worldometers. Total Coronavirus Cases in South Korea. Available online: https://www.worldometers.info/ coronavirus/country/south-korea/ (accessed on 6 October 2020).

20. Porter, M.E. Value Chain. The Value Chain and Competitive Advantage: Creating and Sustaining Superior Performance; Free Press: New York, NY, USA, 1985.

21. Handfield, R.; Nichols, E., Jr. Introduction to Supply Chain Management. Interfaces 1999, 29, 111-114.

22. Sungbae, K.; Taesoo, M. Supply chain integration and collaboration for improving supply chain performance: A dynamic capability theory perspective. In Proceedings of the 49th Hawaii International Conference on System Sciences (HICSS), Koloa, HI, USA, 5-8 January 2016; pp. 307-316.

23. Panahifar, F.; Byrne, P.J.; Salam, M.A.; Heavey, C. Supply chain collaboration and firm's performance. J. Enterp. Inf. Manag. 2018, 31, 358-379. [CrossRef]

24. Mofokeng, T.M.; Chinomona, R. Supply chain partnership, supply chain collaboration and supply chain integration as the antecedents of supply chain performance. S. Afr. J. Bus. Manag. 2019, 50, 1-10. [CrossRef]

25. Errassafi, M.; Abbar, H.; Benabbou, Z. The mediating effect of internal integration on the relationship between supply chain integration and operational performance: Evidence from Moroccan manufacturing companies. J. Ind. Eng. Manag. 2019, 12, 254-273. [CrossRef]

26. Fawcett, S.E.; Magnan, G.M. Ten guiding principles for high-impact SCM. Bus. Horiz. 2004, 47, 67-74. [CrossRef]

27. Kim, J.H.; Park, C.S. The Impact on Supply Chain Integration of Competitive Advantage on Information Communication Technology Capabilities. J. Korea Port Econ. Assoc. 2016, 32, 151-163.

28. Paulraj, A.; Lado, A.A.; Chen, I.J. Inter-organizational communication as a relational competency: Antecedents and performance outcomes in collaborative buyer-supplier relationships. J. Oper. Manag. 2008, 26, 45-64. [CrossRef]

29. Kale, P.; Singh, H.; Perlmutter, H. Learning and protection of proprietary assets in strategic alliances: Building relational capital. Strateg. Manag. J. 2000, 21, 217-237. [CrossRef]

30. Park, C. Emergence of Inter-organizational Collaboration Networks: Relational Capability Perspective. J. Korean Oper. Res. Manag. Sci. Soc. 2015, 40, 1-18.

31. Zacharia, Z.G.; Nix, N.W.; Lusch, R.F. Capabilities that enhance outcomes of an episodic supply chain collaboration. J.Oper. Manag. 2011, 29, 591-603. [CrossRef] 
32. Wittmann, C.M.; Hunt, S.D.; Arnett, D.B. Explaining alliance success: Competences, resources, relational factors, and resource-advantage theory. Ind. Mark. Manag. 2009, 38, 743-756. [CrossRef]

33. Lee, N.; Yoo, S.H.; Jung, D. The Impact of Internal and External Supply Chain Integration on New Product Development. J. Korean Prod. Oper. Manag. 2019, 30, 327-343.

34. Gunasekaran, A.; Patel, C.; McGaughey, R.E. A framework for supply chain performance measurement. Int. J. Prod. Econ. 2004, 87, 333-347. [CrossRef]

35. Tarafdar, M.; Qrunfleh, S. Agile supply chain strategy and supply chain performance: Complementary roles of supply chain practices and information systems capability for agility. Int. J. Prod. Res. 2017, 55, 925-938. [CrossRef]

36. Mani, V.; Gunasekaran, A.; Delgado, C. Enhancing supply chain performance through supplier social sustainability: An emerging economy perspective. Int. J. Prod. Econ. 2018, 195, 259-272. [CrossRef]

37. Zimon, D.; Tyan, J.; Sroufe, R. Implementing Sustainable Supply Chain Management: Reactive, Cooperative, and Dynamic Models. Sustainability 2019, 11, 7227. [CrossRef]

38. Chen, J.; Sohal, A.S.; Prajogo, D.I. Supply chain operational risk mitigation: A collaborative approach. Int. J. Prod. Res. 2013, 51, 2186-2199. [CrossRef]

39. Fan, H.; Li, G.; Sun, H.; Cheng, T. An information processing perspective on supply chain risk management: Antecedents, mechanism, and consequences. Int. J. Prod. Econ. 2017, 185, 63-75. [CrossRef]

40. Zhang, Q.; Cao, M. Exploring antecedents of supply chain collaboration: Effects of culture and interorganizational system appropriation. Int. J. Prod. Econ. 2018, 195, 146-157. [CrossRef]

41. Podsakoff, P.M.; MacKenzie, S.B.; Lee, J.Y.; Podsakoff, N.P. Common method biases in behavioral research: A critical review of the literature and recommended remedies. J. Appl. Psychol. 2003, 88, 879. [CrossRef]

42. Chin, W.W. Commentary: Issues and opinion on structural equation modeling. JSTOR 1998, 22, 7-16.

43. Fornell, C.; Larcker, D.F. Structural Equation Models with Unobservable Variables and Measurement Error: Algebra and Statistics. Sage Publ. 1981, 18, 382-388.

44. Ijaz, M.F.; Rhee, J. Constituents and consequences of Online-shopping in Sustainable E-Business: An experimental study of Online-Shopping Malls. Sustainability 2018, 10, 3756. [CrossRef]

45. Times, G. Protests, Work Resumption Add to Concern of 2nd COVID-19 Wave. Available online: https: //www.globaltimes.cn/content/1190978.shtml (accessed on 3 October 2020).

46. China Global Television Network (CGTN). COVID-19 Global Roundup: Panic Buying in Severely Hit Countries. Available online: https://news.cgtn.com/news/2020-03-03/Coronavirus-outside-China-Panic-buyi ng-in-severely-hit-countries-OyP22Uwjio/index.html (accessed on 3 October 2020).

47. Lee, J. Why is There no Panic Buying in Korea? Available online: http://www.korea.net/NewsFocus/Society/ view? articleId=184370 (accessed on 4 October 2020).

48. Lim, J.Y. Apps Show Mask Inventory for Nearby Locations in Real Time. Available online: http://www.kore aherald.com/view.php?ud=20200313000739 (accessed on 4 October 2020).

49. Bown, C.P. China Should Export More Medical Gear to Battle COVID-19. Available online: https://www.piie.c om/blogs/trade-and-investment-policy-watch/china-should-export-more-medical-gear-battle-covid-19\#_ftn1 (accessed on 6 October 2020).

50. Shih, W.C. Global Supply Chains in a Post-Pandemic World. Harv. Bus. Rev. 2020, 98, 82-89.

51. Kumar, G.; Banerjee, R.; Meena, P.; Ganguly, K.K. Joint planning and problem solving roles in supply chain collaboration. IIMB Manag. Rev. 2017, 29, 45-57. [CrossRef]

52. Chu, S.Y.; Fang, W.C. Exploring the relationships of trust and commitment in supply chain management. J. Am. Acad. Bus. 2006, 9, 224-228.

53. Li, S.; Rao, S.S.; Ragu-Nathan, T.; Ragu-Nathan, B. Development and validation of a measurement instrument for studying supply chain management practices. J. Oper. Manag. 2005, 23, 618-641. [CrossRef]

Publisher's Note: MDPI stays neutral with regard to jurisdictional claims in published maps and institutional affiliations. 